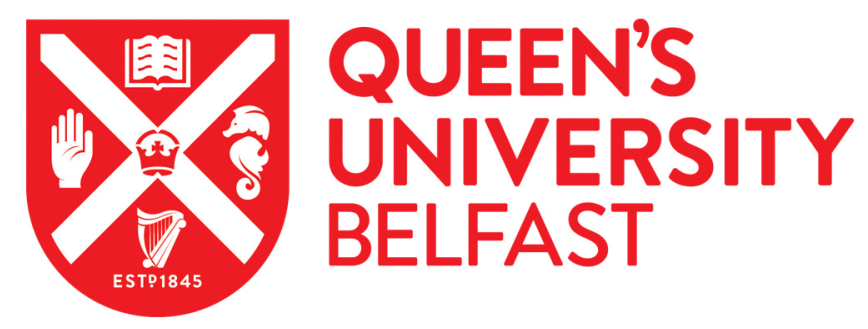

\title{
An Appraisal of End-of-Life Care in Persons with Chronic Kidney Disease Dying in Hospital Wards
}

Noble, H., Brown, J., Shields, J., Fogarty, D., \& Maxwell, A. P. (2015). An Appraisal of End-of-Life Care in Persons with Chronic Kidney Disease Dying in Hospital Wards. Journal of renal care, 41(1), 43-52. https://doi.org/10.1111/jorc.12097

\section{Published in:}

Journal of renal care

\section{Document Version:}

Peer reviewed version

\section{Queen's University Belfast - Research Portal:}

Link to publication record in Queen's University Belfast Research Portal

\section{Publisher rights}

(C) 2014 European Dialysis and Transplant Nurses Association/European Renal Care Association

This is the peer reviewed version of the following article: Noble H., Brown J., Shields J., Fogarty D., Maxwell P.A. (2014). An appraisal of end-of-life care in persons with chronic kidney disease dying in hospital wards. Journal of Renal Care 41(1), 43-52, which has been published in final form at http://onlinelibrary.wiley.com/doi/10.1111/jorc.12097/abstract

This article may be used for non-commercial purposes in accordance with Wiley Terms and Conditions for Self-Archiving.

\section{General rights}

Copyright for the publications made accessible via the Queen's University Belfast Research Portal is retained by the author(s) and / or other copyright owners and it is a condition of accessing these publications that users recognise and abide by the legal requirements associated with these rights.

\section{Take down policy}

The Research Portal is Queen's institutional repository that provides access to Queen's research output. Every effort has been made to ensure that content in the Research Portal does not infringe any person's rights, or applicable UK laws. If you discover content in the Research Portal that you believe breaches copyright or violates any law, please contact openaccess@qub.ac.uk. 
JORC Title page

An appraisal of end-of-life care in persons with Chronic Kidney Disease dying in hospital renal units

Noble HR, Shields JS, Brown J, Maxwell AP, Fogarty, DG.

\section{Statement of authorship:}

HN: Principal Project Leader, conceived study, participated in design and coordination, analysed data, wrote and approved the final manuscript.

JS: Conceived study, participated in design and approved the final manuscript.

JB: Participated in design and coordination, undertook audit, analysed data helped to draft manuscript, read and approved the final manuscript.

APM: Participated in design and coordination, helped to draft manuscript, read and approved the final manuscript.

DGF: Conceived study, participated in design and coordination, helped write the final manuscript. 


\section{An appraisal of end-of-life care in persons with Chronic Kidney Disease dying in hospital renal units}

\section{5 words}

Aim: To review end-of-life care provided by renal healthcare professionals to inpatients with chronic kidney disease, and their carers, over a 12 month period in Northern Ireland.

Methods: Retrospective review of 100 patients.

Results: Mean age at death was 72 years (19-95) and 56\% were male. $83 \%$ of patients had a "Not For Attempted Resuscitation" order during their last admission and the Liverpool Care Pathway for the Dying Patient was implemented in $42 \%$. In only $15 \%$ was there an explicit record that the patient had been told they were dying. Symptoms were recorded in $78 \%$ of patients with $56 \%$ reporting pain, $44 \%$ agitation, $32 \%$ nausea/vomiting and $56 \%$ shortness of breath. Palliative care specialists were involved in the management of $49 \%$ of patients. During the last year of life there was an average of 2.5 admissions per patient (range 1-8) with a median of 28 in-patient days (range 1-233). Carer needs were not formally assessed.

\section{Conclusions:}

End-of-life care for patients with advanced chronic renal disease can be enhanced. There is significant variation in the recording of discussions regarding impending death. There is poor recording of the patients' wishes regarding death and a poor record of who was present with the dying patient in the last days of life.

Those with declining functional status, including those frequently admitted to hospital require holistic assessment regarding end-of-life needs. More effective communication between the patient, family and multi-professional team is required for patients who are dying and those caring for them. These findings are likely to apply to other non-cancer end of life settings and have implications for quality of care and also resources given the days spent in hospital.

\section{Key words}

Chronic kidney disease

End-of-life care

Audit

Palliative care

\section{Background}


The number of persons living with end-stage kidney disease (ESKD) has increased in part due to increased access of an aging population but also due to an increased prevalence of risk factors for chronic kidney disease (CKD) such as diabetes and hypertension (Coresh et al. 2007, Levey et al. 2009). ESKD is a life-limiting condition associated with substantially increased morbidity and premature mortality and affects more than 1500 persons in Northern Ireland (UK Renal Registry, 2012). Over 800 ESKD patients receive maintenance chronic dialysis across Northern Ireland with an annual mortality rate of $16 \%$ in this dialysis population (UK Renal Registry, 2012). In some countries strategies to provide a 'good quality death' in those who are dying have been developed (Quality End-of-Life Care Coalition of Canada. 2010, American Medical Association. 2012, Department of Health, Social Services and Public Safety (DHSSPS) 2010, National End of Life Care Programme 2012).

In Northern Ireland a strategy for end-of-life care for dying adults has been published with the aim of improving palliative care services for all those living with a life-limiting chronic illness (Department of Health, Social Services and Public Safety (DHSSPS) 2010) . Despite this and considerable evidence highlighting the need to improve endof-life care for patients with ESKD, hospitals in Northern Ireland were initially slow to establish pathways and protocols to address end-of-life care in this group..

When older persons with ESKD elect to begin renal replacement therapy they may find this treatment burdensome and disruptive to their quality of life (Noble et al. 2009). Some individuals who are failing to thrive on dialysis may ask to withdraw from treatment following discussion with carers and clinical teams. Alternatively, a person with ESKD may opt for conservative treatment from the outset with palliation of symptoms. This is an area of complex decision making involving the person with ESKD, their family and clinical teams in hospital and primary care settings ((Kidney Care National End of Life Care Progamme 2009)). Palliative care needs have risen in parallel with the increased prevalence of CKD. It is now recognised that palliative and supportive care components of renal services should be developed to support patients dying with kidney disease (Noble et al 2009). This is aptly summarised in a quotation from Dame Cicely Saunders best known for her role in developing hospice and palliative care "You matter because you are you, and you matter to the end of your life. We will do all we can not only to help you die peacefully, but also to live until you die." (Saunders 1976).

Unfortunately palliative care needs of patients with ESKD may go unrecognised, sometimes due to limited knowledge and experience of palliative care principles amongst clinicians (Berzoff et al 2008). Several strategies have been put in place to address this deficiency. These have included clinical guidelines on opioid use in advanced CKD managed without dialysis (Murtagh et al. 2007), guidance on advance care planning (NHS Kidney Care and the NHS National End of Life Care Programme. 2009) and the identification of nominated key workers to support people throughout their disease trajectory to death (Noble \& Lewis 2008). Key Workers 
provide regular care and support and can liaise with other services a patient may require, centralising care (National Institute for Clinical Excellence 2013).

Previously end-of-life care initiatives were primarily focused on those dying from cancer but more recently it has been recognised that persons dying with progressive chronic disease such as renal failure also have supportive and palliative care needs and a requirement for high quality end-of-life care (Hussain et al 2013). Although provision of palliative care services has improved over time, it is recognised end-oflife care may still be deficient for individuals dying from diseases other than cancer (Gott et al. 2007, Small et al. 2009, Murtagh et al. 2011).

\section{Aim:}

The aim of this review was to assess the end-of-life care provided by renal healthcare professionals to hospital in-patients with chronic kidney disease, and their carers, over a 12 month period in Northern Ireland. End-of-life care was assessed relative to Renal Association Guideline 6 related to planning, initiating \& withdrawal of renal replacement therapy (Renal Association 2009). See Box 1. The Renal Association in the United Kingdom (UK) is the professional body for UK renal physicians and renal scientists.

\section{Methods.}

\section{Data collection}

A proforma adapted from McAdoo et al (McAdoo et al. 2011)(McAdoo et al. 2011)(McAdoo et al. 2011), in collaboration with the Guidelines and Audit Implementation Network (GAIN 2014: www.gain-ni.org) in Northern Ireland, was used to collect data related to care at the end-of-life. Data were extracted from the Northern Ireland regional renal information system (eMED, Mediqal) to include demographics, co-morbidities and mobility. The audit included only those patients with advanced CKD who had died in a hospital with on-site renal services in Northern Ireland during the period January 2011- December 2011.

The renal IT Systems Support Officer from the largest hospital trust in the study communicated with Information Managers at the other four Trusts to obtain in-patient deaths during 2011. This information was cross-checked, using Health and Care (NHS) numbers with patients on the renal eMED system, to identify the number of patients with ESKD who had died in hospital. eMED provided information on length of time on Renal Replacement Therapy (RRT), stage of CKD and eGFR at end of life. Secretaries within the five Trusts requested the required medical charts. Deceased patient's notes were stored off-site and most renal patients had multiple charts. Not all charts requested were available with the last admission episode missing in 12 cases. A specialist renal nurse travelled to individual Trusts to collect 
data retrospectively using a combination of the regional Renal data base, eMED, patient's medical notes and regional Patient Administration Systems (PAS).

Additional data retrieved included:

- Details of death including "Not For Attempted Resuscitation" status; mode of dialysis (if used), application of the Liverpool Care Pathway, presence or absence of advance care planning, identification of key worker, patient's preferred place of death. The Liverpool Care Pathway (Ellershaw \& Wilkinson 2003) is a UK multiprofessional document which provides an evidence base for care at the end of life and guidance on ensuring comfort, anticipatory prescribing and appropriate interventions as someone is dying.

- End-of-life planning including whether or not patients and carers were informed of approaching death, involvement of a palliative care team and management of symptoms.

Data were also collected on time spent in hospital in the last year of life and assessment of carers.

\section{Data storage and analysis}

Datasheets were sent to the GAIN study team for data entry and chart generation using Microsoft Excel. Since this study was a chart review audit there were no formal hypotheses to test with statistical tests. Normally distributed variables such as age was reported as mean; skewed data such as hospitalisation as median. Proportions were calculated. Findings were discussed initially with 2 members (HN, DF) of the team who then sent the findings out for discussion.

\section{Findings}

\section{Demographics}

In total, 523 deaths of patients with kidney disease known to a renal team were identified across the five hospital Trusts in Northern Ireland (Table 1). Of these 118 $(22.5 \%)$ occurred on hospital wards, the rest at home, in a hospice, in a nursing home or the Accident and Emergency department. Of the 118 deaths on hospital wards, hospital notes were unavailable for 12 patients, leaving data potentially available on 106 patients. Death was sudden and unforeseen in six patients who experienced cardiopulmonary arrest, leaving the total number included in the audit at 100 . Of the 100 patients the majority were male $(n=56)$ with a mean age of 72 years (range 19-95) and $76 \%$ of patients were over 70 years old. All patients were of white ethnicity. On their final hospital admission $47 \%$ of these patients had ESKD and were receiving renal replacement therapy ( $42 \%$ haemodialysis; $2 \%$ peritoneal 
dialysis; 3\% renal transplant); 29\% had advanced CKD (stage 4 or stage 5) and 24\% had acute kidney injury (Figure 1).

\section{Comorbidity}

The majority (98\%) of patients had at least one co-morbidity including $56 \%$ who had cardiovascular disease, $41 \%$ with diabetes and $24 \%$ with cancer (Table 2). "Other" co-morbidities included rheumatoid arthritis, chronic obstructive airways disease, peripheral vascular disease or liver disease.

\section{Mobility on admission}

The Braden Pressure Ulcer Risk Assessment tool (Bergstrom \& Braden 2002) was used to assess mobility. Seventy-two percent of patients had mobility restrictions. Of this group, $20 \%$ of patients were completely immobile or confined to bed (score 1), $19 \%$ were very limited or chair fast, (score 2); 33\% were slightly limited or walked occasionally (score 3). Only $19 \%$ had no limitations and walked frequently (score 4). Mobility was unknown in $9 \%$ of cases.

\section{Place of residence:}

The majority (82\%) of patients had lived at home prior to their final admission; $11 \%$ in a nursing home; $2 \%$ in assisted living accommodation and in $5 \%$ of cases place of residence was unknown. For those living at home $60 \%$ lived with another family member, $24 \%$ lived alone and in $16 \%$ of cases, this was unknown.

\section{Details of death}

The majority of patients (83\%) had a 'Not For Attempted Resuscitation' order documented during their last admission. A total of 44 patients with ESKD were receiving maintenance dialysis prior to this final admission and a further 17 patients in the AKI and CKD groups commenced dialysis during this admission. Of the 61 patients receiving dialysis, treatment had been discontinued in 30 patients prior to end-of-life. Two patients were directly involved in the discussion about stopping dialysis with medical staff. In those who stopped dialysis the discussion had taken place with the doctor and carer in 23/30 patients. In four cases, it was not documented whether the patient and / or carer was involved in the decision to withdraw dialysis.

\section{End-of-life planning}

It was recorded that $15 \%$ of patients who subsequently died were told they were dying during their last admission. In $68 \%$ of cases there was a record that the family had been informed that the patient was dying. There was a clear record that the aim of care had been changed to palliative management in $70 \%$ of cases. The palliative care team were actively involved with $49 \%$ of patients. In $34 \%$ of cases it was documented that family or carers were present at the time of death. 
In $15 \%$ cases the patient died in the absence of relatives or carers in hospital, and in $51 \%$ of cases it was not documented who was present at death. The Liverpool Care Pathway was used in $42 \%$ of patients. None of the patients had an advanced care plan (ACP). The patient's chosen place of death was specified as 'home' in $7 \%$ of cases but was not documented in $93 \%$. Only one patient had a nominated key worker but in this case the key worker's role was to support mental health needs.

\section{Symptoms at end of life}

Symptoms were documented as assessed in $78 \%$ of patients. Pain was documented in $56 \%$ of patients; agitation was reported in $44 \%$ of patients; shortness of breath in $56 \%$; nausea and vomiting in $32 \%$ cases and pruritus in $2 \%$ of cases (Figure 2). Sixty-three per cent of patients had other symptoms documented including confusion, behaviour problems, urinary incontinence, melaena, diarrhoea, swallowing difficulties, continence problems, constipation, haematemesis, petechial rash, jaundice and abdominal pain.

\section{Time spent in hospital}

The average number of admissions in the last year of life was 2.5 (range 1-8). 60\% had 1-2 admissions; 31\% had 3-4 admissions, 6\% had 5-6 admissions and 3\% patients had $>7$ admissions (Figure 3 ). The median number of days in hospital was 28 (range 1-233); 22\% <10 days, 14\% 11-20 days, 17\% 21-30 days, 19\% 31-40 days, $11 \% 41-50$ days and $17 \%$ of patients spent more than 51 days as an in-patient during their last year of life (Figure 4).

\section{Assessment of carers.}

No carer had a formal assessment of their needs recorded in the hospital notes. Where the Liverpool Care Pathway had been utilised carers were offered some practical information relating to car parking and toilets within the hospital.

\section{Discussion}

The findings from this work reinforce the need to continue to improve the care offered to patients with renal disease who are dying. This is likely to the case for other chronic disease areas such as heart and respiratory failure given our previous work identifying unmet needs in patients and carers (Fitzsimons et al 2007). Areas to focus on include helping patients to plan for approaching death, identifying death in a timely fashion, identifying and managing symptoms as the end-of-life approaches, assessing and supporting carers and appropriate recording and auditing of these events. Interesting only 118 out of 523 deaths of patients with kidney disease known to a renal team occurred on hospital wards. Although this number might indicate that many deaths had occurred at home and had been planned for, this is unlikely. It is well-known that sudden death in the renal population is common and renal units have high numbers of unexpected deaths (Keith et al 2004). In this study seven patients had indicated their preferred place of death as 
home. This is likely to have been an underestimate given some study reports indicating preference for home death up to $100 \%$ of participants (Higginson, \& SenGupta 2000). Unfortunately, their condition deteriorated when their preferred place was communicated and none were deemed fit for transfer home. Future work should include identifying the place of death ofr patietsn who die in and out of hospital and whether or not the death was expected.

In this review there were no patients with an ACP although $42 \%$ had been placed on the LCP. Advanced Care Planning is recommended in national End Of Life Strategies in the UK (Department of Health 2008; Department of Health 2010; Scottish Government Health Department 2008; Department of Health, Social Services and Public Safety 2010) and by the Renal Association (Renal Association 2009). It involves the process of ongoing discussion, reflection, understanding and communication between a patient, their family and healthcare staff, for the purpose of clarifying values, treatment preferences and goals for end of life care (Davison 2009). ACP can help patients avoid inappropriate prolongation of dying and achieve a sense of control (Kurella Tamura et al. 2010) and is concerned with discussion of people's preferences and what they might wish to happen if their health deteriorated. An ACP should be commenced prior to people becoming unwell so they are capable of making informed decisions. While ACP has been promoted positively in renal patients (Davison 2009), some nephrologists are uncomfortable initiating discussions about end of life care (Davison 2006). They may also be wary of ACP as patients are not always consistent about their wishes and may change their minds depending on their current health status, cognitive and psychological state (ref). Work in this area is limited but a study by Silvester et al (2013) found that the implementation of ACP enabled the documentation and respecting of patients wishes and more patients receiving treatments that were in their best interest. Patients and families need to be informed at time of diagnosis that ESRD is a life-limiting illness, to enable them to plan for the impact of this illness (ref). Prognosis is difficult in renal disease and physicians may believe that patients do not want to engage in these discussions and fear taking away the patient's hope (Fassett 2011), yet few data support the notion that providing truthful information will destroy hope (Michel \& Moss 2005). In Davison's study (2006) which explored perspectives of patients with advanced CKD on ACP, patients said they wanted more information and earlier instigation of ACP discussions. The ability to listen empathetically was viewed as central to ACP as was the role of physicians in initiating discussions and guiding the ACP process. Although no patients had an ACP, $42 \%$ had been commenced on the LCP (Marie Curie 2008) which aimed to increase a patients' involvement in their care (van der Heide et al 2009). This aside, open communication with the patient appeared unsatisfactory in this study. For example, while 23 carers were involved in the discussion related to withdrawal of dialysis, only two patients had the opportunity to participate in this conversation. In 68 cases, the family were told the patient was dying, but only 15 patients had been explicitly told they were dying. In some cases the patient was unconscious before the conversation occurred and so the patient 
was unable to participate. The LCP provided useful data for this audit but has been rapidly phased out of clinical use during 2013 due to concerns about its wider misuse in clinical practice (BMJ. 2013).

Holistic assessment of patient and carer's needs is a recommendation in the end of life strategy (Department of Health 2008; Department of Health 2010; Scottish Government Health Department 2008; Department of Health, Social Services and Public Safety 2010). Despite this, there was no record of any carer having undergone a formal assessment of their needs in this review. Low et al (2008) explored the impact of kidney disease on close persons, and highlighted only one study that assessed the long term impact of death on families, despite professionals awareness of the additional support offered by family members to renal patients throughout many years of illness. Brown et al (2008) suggest that support for families during the last illness, improves the quality of the death. Appropriate end-of-life care, tailored to the individual needs of the person who is dying and to their family, can and must be achieved. Again, as Dame Cicely Saunders, is quoted as saying "How people die lives on in the memory of those who live on" (Saunders 1989) .

This work highlights a high symptom burden in patients dying with advanced kidney disease. Several studies have shown that patients with advanced kidney disease suffer a symptom burden similar to patients dying of cancer (Murtagh et al. 2010, Saini et al. 2006). Similarities are reflected in Murtagh et al's work (2011) which reported a sharp increase in symptom distress and suffering and number of symptoms by patients as death approached. In our study group of 100 patients, 78 had documentation reflecting the excessive symptom burden experienced by renal patients at the end of life. Where symptom burden had been difficult to manage help was sought from the specialist palliative care team in almost half of patients (49\%). Nevertheless, more needs to be done to reduce symptom burden in this population. Health care professionals need to anticipate and address symptoms, some of which may indicate the patient is approaching death (Murtagh et al. 2011). Also use of health related quality of life (HRQOL) and functional assessment tools have been shown to help identification of those whose health is declining.(Murphy et al 2010; Davison 2007)). Tools such as the Patient Outcome Scale - Symptoms (POS-S) include renal specific symptoms (Murtagh et al. 2010). Scores can guide introduction of symptoms algorithms to ensure suitable medication prescribed and emotional support can be offered if indicated to improve symptoms and QOL long before patients reach the end of life stage. Promoting appropriate end-of-life care, tailored to the needs of an individual and their family, can be achieved by further education of professionals and the general public. Improved understanding of the principles and intentions of end-of-life care, may improve confidence and subsequently increase implementation of best practice across both acute and community settings (McAdoo et al. 2011). 


\section{Implications for practice}

From this study several recommendations for practice are suggested. Introduction of quality of life and functional assessment tools may help in identifying those whose health is declining and symptoms arising. Scores may also be helpful for difficult conversations such as those related to Advanced Care Planning and may help to reduce hospital admissions and deaths in hospital (McAdoo et al 2011). At risk registers should be developed for chronic dialysis and transplant patients and suggested triggers may include two or more non-elective admissions in the last year; weight loss of 5-10\% on dialysis not connected with fluid losses; cognitive decline that worries family and staff and moving residence into nursing homes. Linked with the community, this will improve communication with the multidisciplinary team and help plan the preferred options for end of life care. The recent introduction of regional Renal Clinical Prognostic Indicators in Northern Ireland, to support Renal Association Guidelines (ref), may assist with identification of patients who are likely to be entering their last year of life. It is advised that these patients are placed on a register linked to the community GP surgery. This strategy may assist in improving discussions and planning with patients who are entering the final phase of life in the absence of formal ACP.

End-of-life Strategies recommend holistic support for patients and carers. This may include emotional and practical support for both parties. Assessment will help identify individual needs of the carer, including need for respite care for example when carers are taken ill and unable to offer care to patient.

All health and social care staff should be offered appropriate training and support by experienced renal and palliative care teams. This will improve confidence among all levels of general ward staff in caring for dying renal patients and promote insight into their needs.

Patients requiring supportive and palliative care should be referred for appropriate psychosocial and symptom support until death. All patients should have a key worker to help improve communication between hospital, carers and the community team. A renal supportive care team, supported by the specialist palliative care team could offer a dedicated out-patient clinic coordinating multidisciplinary care in the community for those patients likely to be in their last year of life.

This audit is a first step in exploring death and dying in a renal population in Northern Ireland. The audit has highlighted areas for further audit and research. In particular we are aware that the needs of patients and carers with acute kidney injury are different. Furthermore this group of patients have more uncertainty about their prognosis and further work is required to see if there are better predictors for end-of 
life identification in this group. Discussion with intensive care and acute medicine colleagues may help this.

\section{Limitations of the work}

The proforma collection tool had three sections. The third section covered "End-ofLife Planning" which included collection of information relating to, "admissions in last year of life" and the "number of in-patient days in the last year of life". Due to data protection issues, this information could only be collected from the five hospital Trusts with renal units. Consequently, the total number of admissions and in-patient days this group of patients may have spent in other hospitals in Northern Ireland during their last year of life could not be completely identified. The proformas were completed retrospectively and relied on relevant and factual information being available and accessed from patients' hospital notes. Variation in how notes were completed was seen in many patients with more detail being available in some compared to others.

\section{Conclusion}

This case note review demonstrates that end-of-life care for patients with renal disease can be improved. Those with declining functional status including those who have frequent hospital admissions require holistic assessment of their end-of -life needs. Effective communication between the patient, family and multi-professional team is essential.

\section{References}

disease patients managed without dialysis", Journal of pain and symptom management, vol. 40, no. 3, pp. 342-352. References

American Medical Association. (2012) AMA policy on end of life care, http://www.ama-assn.org/ama/pub/physician-resources/medical-ethics/aboutethics-group/ethics-resource-center/end-of-life-care/ama-policy-end-of-lifecare.page (Accessed 27.11.13)

Bergstrom N, Braden BJ (2002). Predictive validity of the Braden Scale among Black and White subjects. Nursing Research. 51(6):398-403. 
Berzoff J, Swantkowski J, Cohen LM (2008). Developing a renal supportive care team from the voices of patients, families, and palliative care staff. Palliat.

Support. Care; 6: 133-9

Brown EA, Chambers JE, Eggeling C (2008). Palliative Care in Nephrology. Nephrology Dialysis Transplantation. 23 (3):789-791.

Coresh J, Selvin E, Stevens L. et al. (2007) Prevalence of Chronic Kidney Disease in the United States. JAMA, 298 (17) 2038-2047.

Davison S.N (2006). Advanced care planning in patients with end-stage renal disease. Progress in Palliative Care. Vol17 No4 pp. 170-178

Davison SN. Facilitating advance care planning for patients with end-stage renal disease: the patient perspective. Clinical Journal of the American Society of Nephrology 1(5):1023-8.

Department of Health, Social Services and Public Safety (DHSSPS) (2010). Living Matters: Dying Matters. A Palliative and End of Life Care Strategy for Adults in Northern Ireland. http://www.dhsspsni.gov.uk/8555 palliative final.pdf (Accessed 27.11.13).

Department of Health (2008). End of Life Care Strategy for Adults. DH, 2008. www.endoflifecareforadults.nhs.uk/eolc

Ellershaw JE, Wilkinson S, eds (2003) A Pathway to Excellence. Oxford University Press, Oxford

Fitzsimons D, Mullan D, Wilson JS, Conway B, Corcoran B, Dempster M, Gamble J, Stewart C, Rafferty S, McMahon M, MacMahon J, Mulholland P, Stockdale P, Chew E, Hanna L, Brown J, Ferguson G, Fogarty D. The challenge of patients' unmet palliative care needs in the final stages of chronic illness (2007) Palliative Medicine Jun;21(4):313-22.

Gott M, Barnes S, Parker C, et al (2007). Dying trajectories in heart failure. Palliative Medicine. 21: 95-99.

Higginson I,\& Sen-Gupta, GJ (2000). Place of care in advanced cancer: A qualitative systematic literature review of patient preferences. Journal of Palliative Medicine 3:287-300.

Hussain J.A., Mooney A., Russon L. (2013) Comparison of survival analysis and palliative care involvement in patients aged over 70 years choosing conservative management or renal replacement therapy in advanced chronic kidney disease Palliative Medicine, 27 (9) , pp. 829-839.

Kurella Tamura M, Goldstein MK. \& Perez-Stable EJ. (2010) Preferences for dialysis withdrawal and engagement in advance care planning within a diverse sample of dialysis patients, Nephrology, dialysis, transplantation : official 
publication of the European Dialysis and Transplant Association - European Renal Association.,25 (1): 237-242.

Levey AS, Schoolwerth AC, Burrows NR (2009) Comprehensive Public Health Strategies for Preventing the Development, Progression, and Complications of CKD: Report of an Expert Panel Convened by the Centers for Disease Control and Prevention, American Journal of Kidney Diseases. 53(3) 522-535.

Low J, Smith G, Burns A, et al (2008) The Impact of ESKD on close persons: a literature review. NDT Plus. 2:67-79.

McAdoo SP, Brown EA, Chesser AM, et al \& on behalf of pan-Thames renal audit group (2012) Measuring the quality of end of life management in patients with advanced kidney disease: results from the pan-Thames renal audit group, Nephrology Dialysis Transplantation. 27(4): 1548-54.

Michel, MD. Moss , AH (2005). Communicating Prognosis in the Dialysis Consent Process: A patient-centred, Guideline-Supported Approach.

Advances in Chronic Kidney Disease, Vol 12, No 2 pp 196-201

Murtagh FE, Vinen K, Farrington K et al (2011). Living and dying with COPD. End of life trajectories across conditions, BMJ (Clinical research ed.). 15 (342): 989

Murtagh, F.E., Addington-Hall, J., Edmonds, P., Donohoe, P., Carey, I., Jenkins, K. \& Higginson, I.J. (2010)"Symptoms in the month before death for stage 5 chronic kidney

Murtagh FEM, Chai M, Donohue P (2007). The use of opioid analgesia in endstage renal disease patients managed without dialysis: recommendations for practice, Journal of Pain \& Palliative Care Pharmacotherapy. 21(2): 5-16.

National End of Life Care Programme (2012) Transforming end of life care in acute hospitals: The route to success 'how to' guide. Available:

http://www.endoflifecare.nhs.uk/search-resources/resourcessearch/publications/imported-publications/transforming-end-of-life-care-in-acutehospitals.aspx (Accessed 27.11.13).

NHS Kidney Care and the NHS National End of Life Care Programme (2009). End of Life Care in Advanced Kidney Disease: A Framework for Implementation, $\mathrm{DOH}$, London

National Institute for Clinical Excellence (2013) Key Worker http://www.nice.org.uk/guidance/qualitystandards/breastcancer/KeyWorker.jsp Accessed 30.1.14

Noble H \& Lewis R (2008) The Role of the nurse caring for dying renal patients. Nursing Times 104 (23): 26-27 
Noble H, Meyer J, Kelly D et al (2009). Reasons renal patients give for deciding not to dialyse: prospective qualitative interview study, Dialysis \& Transplantation, 38 (3): 82-89.

Northern Ireland Kidney Research Fund (2012). Northern Ireland Kidney Research Fund. Research. Available:

http://www.kidneyresearchni.com/research.aspx (Accessed 27.11.13).

Quality End-of-Life Care Coalition of Canada (2010). Blueprint for action 20102012, Quality End-of-Life Care Coalition of Canada, Canada.

Renal Association (2009). Planning, Initiating and Withdrawal of Renal Replacement Therapy http://www.renal.org/Libraries/Guidelines/RRT Current version - 17 September 2009 FINAL.sflb.ashx (Accessed 27.11.13).

Saunders C (1989) Pain and impending death, in Textbook of Pain, eds. P. Wall \& R. Melzak, 2nd edn, Churchill Livingstone, Edinburgh, UK. 624-631.

S

aunders C (1976) Care of the Dying: The Problem of Euthanasia. Nursing Times. 72(26): 1003-1005.

Scottish Government Health Department. Living and Dying Well: A national action plan for palliative and end of life care in Scotland. Scottish Government, 2008. www.scotland.gov.uk/Topics/Health/NHS-Scotland/LivingandDyingWell. (Accessed 3.3.14)

Small N, Barnes S, Gott M et al (2009). Dying, death and bereavement: a qualitative study of the views of carers of people with heart failure in the UK, BMC Palliative Care. 8(6) http://www.biomedcentral.com/1472-684X/8/6

Accessed 27.11.13 


\begin{tabular}{|l|l|}
\hline Demographics and mode of RRT & Number of patients (\%) \\
\hline Gender & \\
\hline Male & $56(56)$ \\
\hline Female & $44(44)$ \\
\hline Age (years) & \\
\hline$<30$ & $1(1)$ \\
\hline $30-59$ & $14(14)$ \\
\hline $60-69$ & $12(12)$ \\
\hline $70-79$ & $48(48)$ \\
\hline $80-89$ & $26(26)$ \\
\hline $90+$ & $5(5)$ \\
\hline Ethnicity & \\
\hline Caucasian & $100(100)$ \\
\hline Mode of RRT on Admission & \\
\hline HD & $42(42)$ \\
\hline PD & $2(2)$ \\
\hline Transplant & $3(3)$ \\
\hline AKI & $24(24)$ \\
\hline CKD & $29(29)$ \\
\hline
\end{tabular}

Table 1: Demographics and mode of RRT of the study population (HD=haemodialysis; $P D=$ =eritoneal dialysis; $A K I=$ acute kidney injury; $C K D=c h r o n i c$ kidney disease)

Stages of Kidney Disease

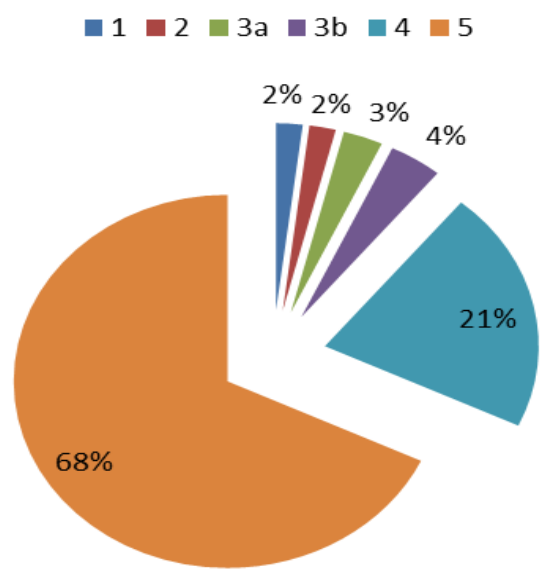

Figure 1: Stage of kidney disease at time of death 


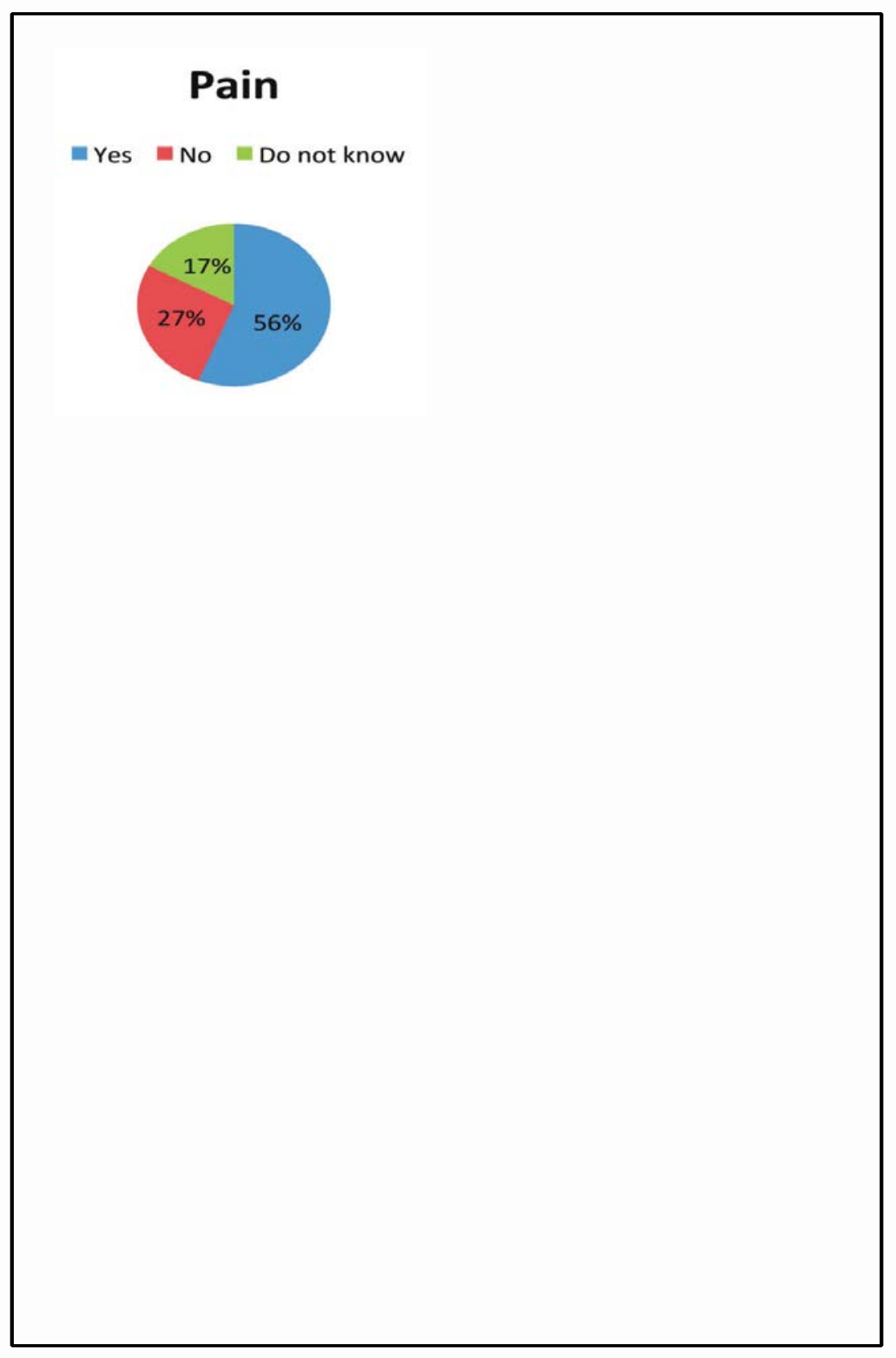

Figure 2: Symptoms at the end of life

16 


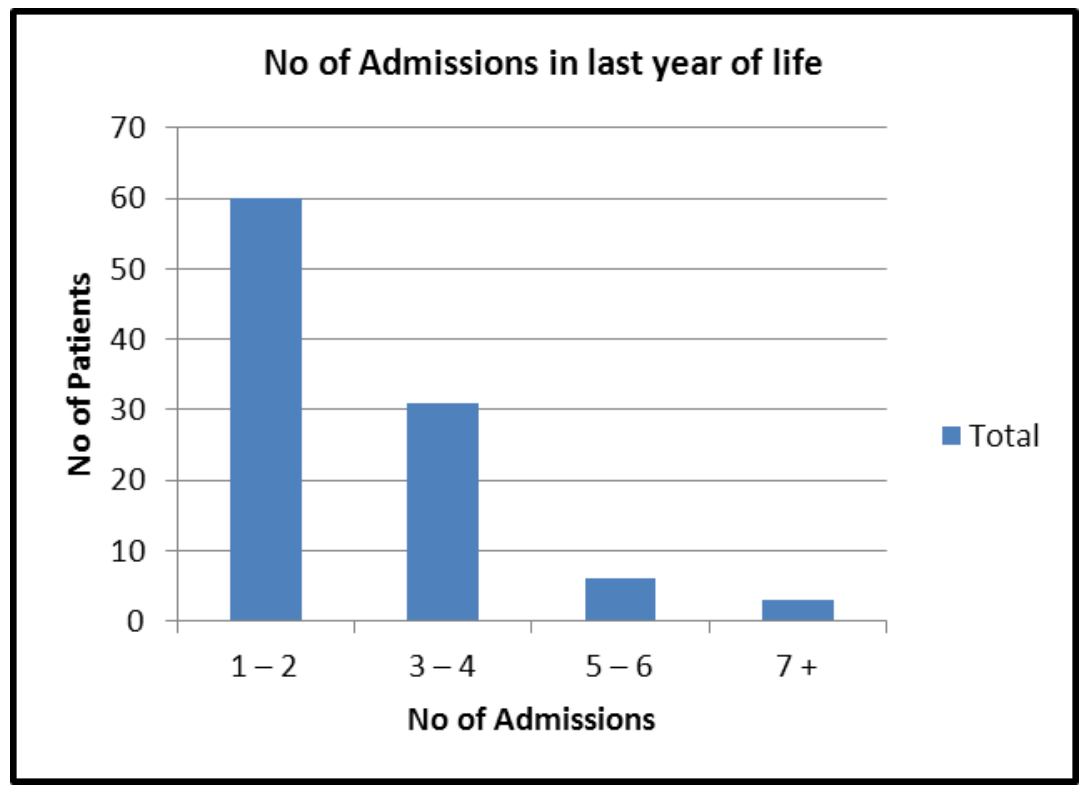

Figure 3: Number of admissions in last year of life



Figure 4: Number of inpatient days in last year of life

\begin{tabular}{|c|c|}
\hline Co-morbidities & No. of Patients (n=100) \\
\hline Cardiovascular Disease Only & $3(3 \%)$ \\
\hline Diabetes Mellitus Only & - \\
\hline Other & $28(28 \%)$ \\
\hline Cardiovascular Disease + Diabetes Mellitus & $6(6 \%)$ \\
\hline Cardiovascular Disease + Other & $26(26 \%)$ \\
\hline Diabetes Mellitus + Other & $14(14 \%)$ \\
\hline $\begin{array}{c}\text { Cardiovascular Disease + Diabetes Mellitus } \\
+ \text { Other }\end{array}$ & $21(21 \%)$ \\
\hline Unknown & $2(2 \%)$ \\
\hline
\end{tabular}

Table 2 Co-morbidities 
Table 3: End of life planning

Acknowledgement

We acknowledge the support of the Guidelines \& Audit Implementation Network (GAIN) in Northern Ireland who funded this work.American Medical Association. (2012)AMA policy on end of life care, http://www.ama-

assn.org/ama/pub/physician-resources/medical-ethics/about-ethics-group/ethicsresource-center/end-of-life-care/ama-policy-end-of-life-care.page edn. 
BMJ. 2013, , Bad press over Liverpool care pathway has scared patients and doctors, say experts. Available: http://www.bmj.com/content/346/bmj.f175 [2013, 01/29].

Coresh, J., Selvin, E., Stevens, L. \& et al. (2007)"Prevalence of Chronic Kidney Disease in the United States.", JAMA, vol. 298, no. 17, pp. 2038-2047.

Department of Health, Social Services and Public Safety (DHSSPS) 2010, , Living Matters: Dying Matters. A Palliative and End of Life Care Strategy for Adults in Northern Ireland, 2010. Available:

www.endoflifecareforadults.nhs.uk/publications/living-matters-dying-matters-apalliative-and-end-of-life-care-strategy-for-adults-in-northern-ireland (accessed 10 January 2011).

Gott, M., Barnes, S., Parker, C., Payne, S., Seamark, D., Gariballa, S. \& Small, N. (2007)"Dying trajectories in heart failure", Palliative medicine, vol. 21, pp. 95-99.

Kidney Care National End of Life Care Progamme 2009, End of Life Care in Advanced Kidney Disease: A Framework for Implementation, DH, London.

Kurella Tamura, M., Goldstein, M.K. \& Perez-Stable, E.J. (2010)"Preferences for dialysis withdrawal and engagement in advance care planning within a diverse sample of dialysis patients", Nephrology, dialysis, transplantation : official publication of the European Dialysis and Transplant Association - European Renal Association, vol. 25, no. 1, pp. 237-242.

Levey, A.S., Schoolwerth, A.C., Burrows, N.R., Williams, D.E., Stith, K.R. \& McClellan, W. (2009)"Comprehensive Public Health Strategies for Preventing the Development, Progression, and Complications of CKD: Report of an Expert Panel Convened by the Centers for Disease Control and Prevention", American Journal of Kidney Diseases, vol. 53, no. 3, pp. 522-535.

Marie Curie 2008, , Liverpool Care Pathway for the Dying Patient (LCP).

McAdoo, S.P., Brown, E.A., Chesser, A.M., Farrington, K., Salisbury, E.M. \& on behalf of pan-Thames renal audit group (2011)"Measuring the quality of end of life management in patients with advanced kidney disease: results from the panThames renal audit group", Nephrology Dialysis Transplantation, .

Murtagh, F.E., Addington-Hall, J., Edmonds, P., Donohoe, P., Carey, I., Jenkins, K. \& Higginson, I.J. (2010)"Symptoms in the month before death for stage 5 chronic kidney disease patients managed without dialysis", Journal of pain and symptom management, vol. 40, no. 3, pp. 342-352.

Murtagh, F.E., Vinen, K., Farrington, K. \& O'Donoghue, D. (2011)"Living and dying with COPD. End of life trajectories across conditions", BMJ (Clinical research ed.), vol. 342, pp. d989. 
Murtagh, F.E.M., Chai, M., Donohue, P., Edmonds P.M \& Higginson, I.J. (2007)"The use of opioid analgesia in end-stage renal disease patients managed without dialysis: recommendations for practice", Journal of Pain \& Palliative Care Pharmacotherapy, vol. 21, no. 2, pp. 5-16.

National End of Life Care Programme 2012, , Transforming end of life care in acute hospitals: The route to success 'how to' guide. Available: http://www.endoflifecareforadults.nhs.uk/publications/acute-rts-howtoguide [2012, 03/05].

NHS Kidney Care and the NHS National End of Life Care Programme. 2009, End of Life Care in Advanced Kidney Disease: A Framework for Implementation, DOH, London.

Noble, H., Meyer, J., Kelly, D., Johnson, B. \& Bridges, J. (2009)"Reasons renal patients give for deciding not to dialyse: prospective qualitative interview study", Dialysis \& Transplantation, vol. 38, no. 3, pp. 82-89.

Quality End-of-Life Care Coalition of Canada. 2010, Blueprint for action 2010-2012, Quality End-of-Life Care Coalition of Canada, Canada.

Saini, T., Murtagh, F., Dupont, P., McKinnon, P., Hatfield, P. \& Saunders, Y. (2006)"Comparative pilot study of symptoms and quality of life in cancer patients and patients with end stage renal disease", Palliative medicine, vol. 20, pp. 631636.

Silvester W, Mawren D, Detering \& , Walli K (2013) K ACPEL abstracts-Chronic Disease: The Impact of Advance Care Planning for Renal Patients BMJ Supportive and Palliative Care 3:2 246-247

Saunders, C. 1989, "Pain and impending death" in Textbook of Pain, eds. P. Wall \& R. Melzak, 2nd edn, Churchill Livingstone, Edinburgh, UK, pp. 624-631.

Saunders, C. (1976)"Care of the Dying: The Problem of Euthanasia", Nursing Times, vol. 72 , no. 26 , pp. 1003-1005.

Small, N., Barnes, S., Gott, M., Payne, S., Parker, C., Seamark, D. \& Gariballa, S. (2009)"Dying, death and bereavement: a qualitative study of the views of carers of people with heart failure in the UK", BMC Palliative Care, vol. 8, no. 1, pp. 6.

American Medical Association. (2012)AMA policy on end of life care, http://www.ama-assn.org/ama/pub/physician-resources/medical-ethics/aboutethics-group/ethics-resource-center/end-of-life-care/ama-policy-end-of-lifecare.page edn.

BMJ. 2013, , Bad press over Liverpool care pathway has scared patients and doctors, say experts. Available: http://www.bmj.com/content/346/bmj.f175 [2013, 01/29]. 
Coresh, J., Selvin, E., Stevens, L. \& et al. (2007)"Prevalence of Chronic Kidney Disease in the United States.", JAMA, vol. 298, no. 17, pp. 2038-2047.

Department of Health, Social Services and Public Safety (DHSSPS) 2010, , Living Matters: Dying Matters. A Palliative and End of Life Care Strategy for Adults in Northern Ireland, 2010. Available:

www.endoflifecareforadults.nhs.uk/publications/living-matters-dying-matters-apalliative-and-end-of-life-care-strategy-for-adults-in-northern-ireland (accessed 10 January 2011).

Gott, M., Barnes, S., Parker, C., Payne, S., Seamark, D., Gariballa, S. \& Small, N. (2007)"Dying trajectories in heart failure", Palliative medicine, vol. 21, pp. 95-99.

Kidney Care National End of Life Care Progamme 2009, End of Life Care in Advanced Kidney Disease: A Framework for Implementation, DH, London.

Kurella Tamura, M., Goldstein, M.K. \& Perez-Stable, E.J. (2010)"Preferences for dialysis withdrawal and engagement in advance care planning within a diverse sample of dialysis patients", Nephrology, dialysis, transplantation : official publication of the European Dialysis and Transplant Association - European Renal Association, vol. 25, no. 1, pp. 237-242.

Levey, A.S., Schoolwerth, A.C., Burrows, N.R., Williams, D.E., Stith, K.R. \& McClellan, W. (2009)"Comprehensive Public Health Strategies for Preventing the Development, Progression, and Complications of CKD: Report of an Expert Panel Convened by the Centers for Disease Control and Prevention", American Journal of Kidney Diseases, vol. 53, no. 3, pp. 522-535.

Marie Curie 2008, , Liverpool Care Pathway for the Dying Patient (LCP).

McAdoo, S.P., Brown, E.A., Chesser, A.M., Farrington, K., Salisbury, E.M. \& on behalf of pan-Thames renal audit group (2011)"Measuring the quality of end of life management in patients with advanced kidney disease: results from the panThames renal audit group", Nephrology Dialysis Transplantation, .

Murtagh, F.E., Addington-Hall, J., Edmonds, P., Donohoe, P., Carey, I., Jenkins, K. \& Higginson, I.J. (2010)"Symptoms in the month before death for stage 5 chronic kidney disease patients managed without dialysis", Journal of pain and symptom management, vol. 40, no. 3, pp. 342-352.

Murtagh, F.E., Vinen, K., Farrington, K. \& O'Donoghue, D. (2011)"Living and dying with COPD. End of life trajectories across conditions", BMJ (Clinical research ed.), vol. 342, pp. d989.

Murtagh, F.E.M., Chai, M., Donohue, P., Edmonds P.M \& Higginson, I.J. (2007)"The use of opioid analgesia in end-stage renal disease patients managed without dialysis: recommendations for practice", Journal of Pain \& Palliative Care Pharmacotherapy, vol. 21, no. 2, pp. 5-16. 
Murtagh, F.E.M., Sheerin, N.S., Addington-Hall, J. \& Higginson, I.J.

(2011)Trajectories of Illness in Stage 5 Chronic Kidney Disease: A Longitudinal Study of Patient Symptoms and Concerns in the Last Year of Life.

National End of Life Care Programme 2012, , Transforming end of life care in acute hospitals: The route to success 'how to' guide. Available: http://www.endoflifecareforadults.nhs.uk/publications/acute-rts-howtoguide [2012, 03/05].

NHS Kidney Care and the NHS National End of Life Care Programme. 2009, End of Life Care in Advanced Kidney Disease: A Framework for Implementation, DOH, London.

Noble, H., Meyer, J., Kelly, D., Johnson, B. \& Bridges, J. (2009)"Reasons renal patients give for deciding not to dialyse: prospective qualitative interview study", Dialysis \& Transplantation, vol. 38, no. 3, pp. 82-89.

Quality End-of-Life Care Coalition of Canada. 2010, Blueprint for action 2010-2012, Quality End-of-Life Care Coalition of Canada, Canada.

Saini, T., Murtagh, F., Dupont, P., McKinnon, P., Hatfield, P. \& Saunders, Y. (2006)"Comparative pilot study of symptoms and quality of life in cancer patients and patients with end stage renal disease", Palliative medicine, vol. 20, pp. 631636.

Saunders, C. 1989, "Pain and impending death" in Textbook of Pain, eds. P. Wall \& R. Melzak, 2nd edn, Churchill Livingstone, Edinburgh, UK, pp. 624-631.

Saunders, C. (1976)"Care of the Dying: The Problem of Euthanasia", Nursing Times, vol. 72 , no. 26 , pp. 1003-1005.

Small, N., Barnes, S., Gott, M., Payne, S., Parker, C., Seamark, D. \& Gariballa, S. (2009)"Dying, death and bereavement: a qualitative study of the views of carers of people with heart failure in the UK", BMC Palliative Care, vol. 8, no. 1, pp. 6. 